رئوف مصطفىزاده'، خديجه حاجى '، اباذر اسمعلىعورى 'و شهناز ميرزايىع

\author{
1 - استاديار، دانشكده كشاورزى و منابع طبيعى، دانشگاه محقق اردبيلى،

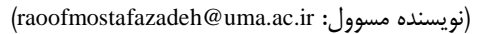 \\ r، ז و أ- دانشجوى كارشناسىارشد، دانشيار و دانشآموخته كارشناسىارشد، دانشكده كشاورزى و منابع طبيعى، دانشعاه محقق اردبيلى \\ تاريخ دريافت:
}

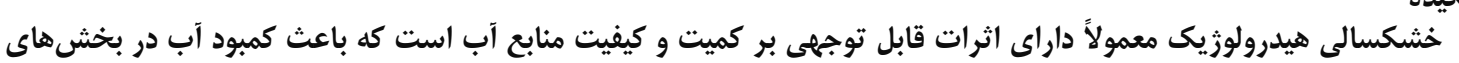

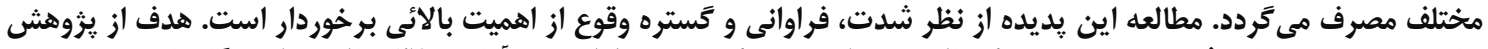

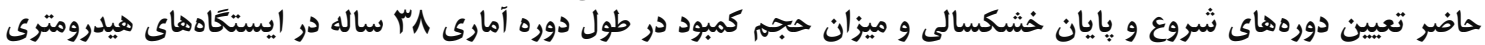

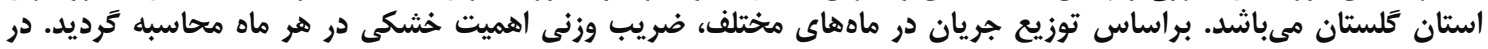

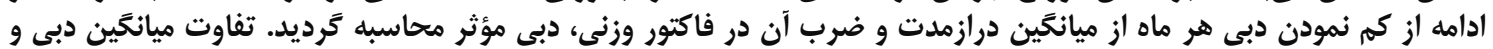

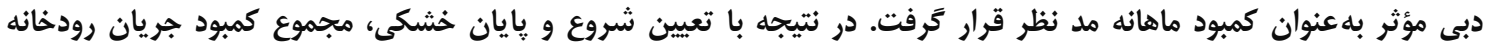

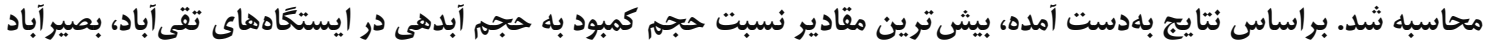

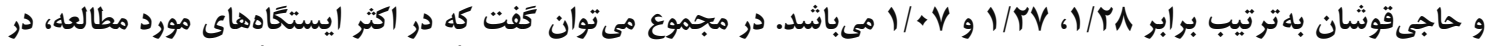

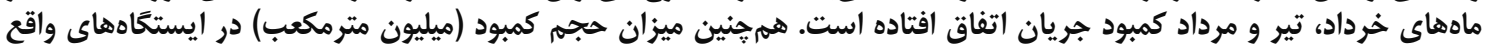

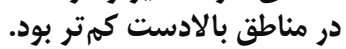

وازههاى كليدى: تغييرات جريان، حجم كمبود، حد آستانه، خشكسالى هيدرولوزيك، كمبود جريان

مختلف حوزه آبخيز رودخانه كرخه يكسان نبوده است. روند

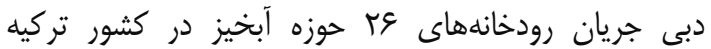

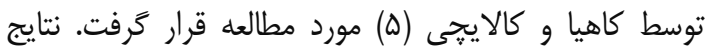

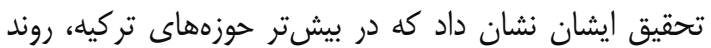

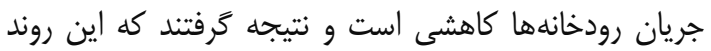

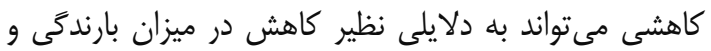

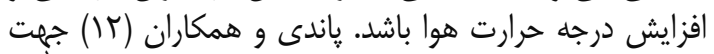

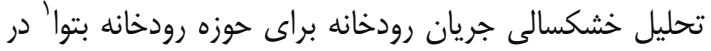

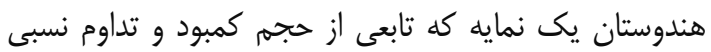

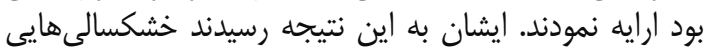

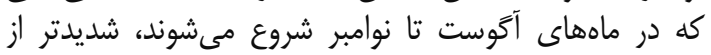

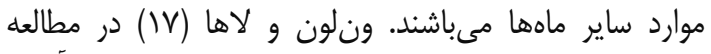

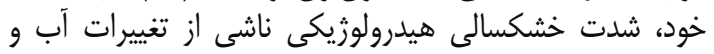

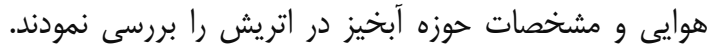

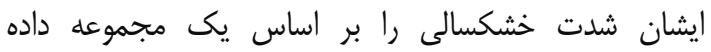

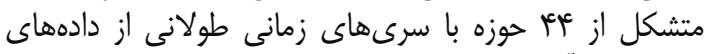

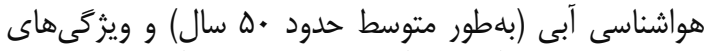

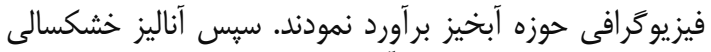

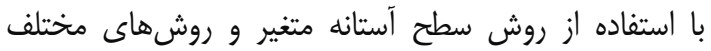

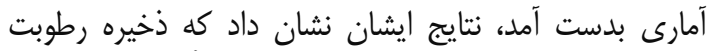

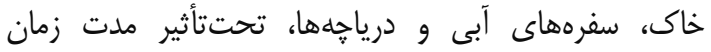

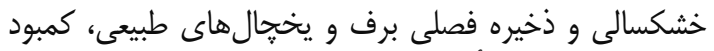

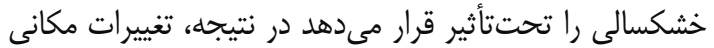

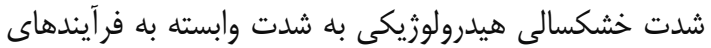

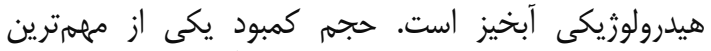

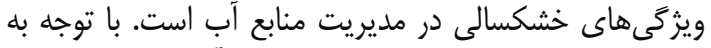

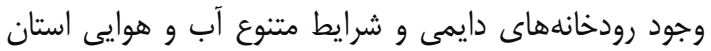

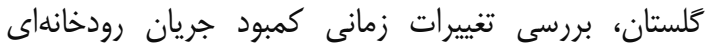

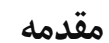

خشكسالى از جمله مخاطرات اقليمى است كه منجر به به

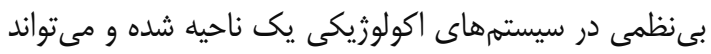

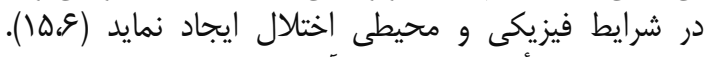

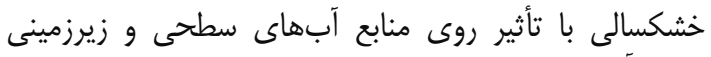

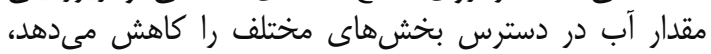

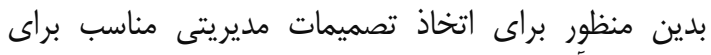

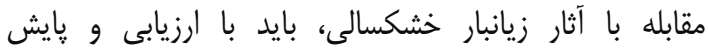

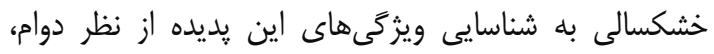

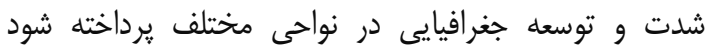

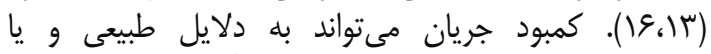

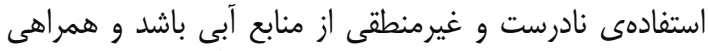

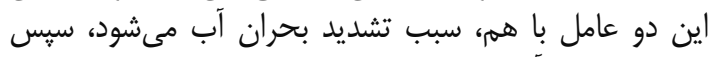

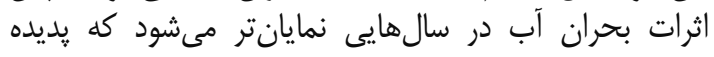

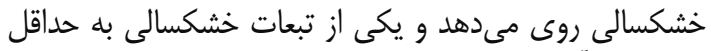

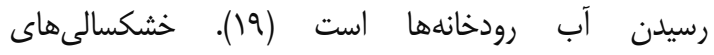

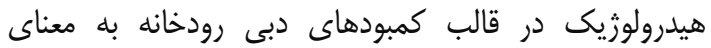

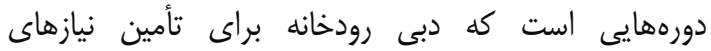

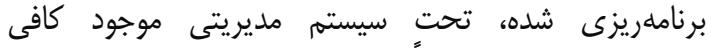

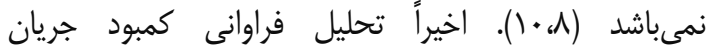

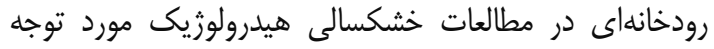

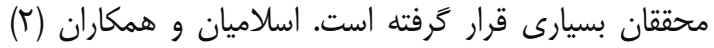

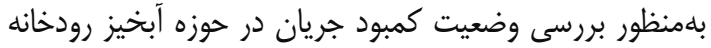

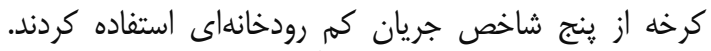

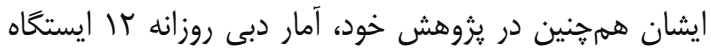

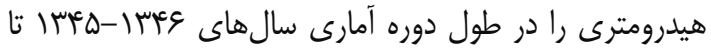

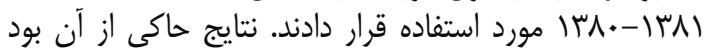
كه سالهاى وقوع خشكسالى هيدرولوزيك در ايستخاههاى داني 


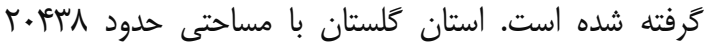

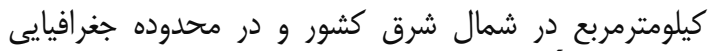

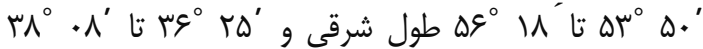

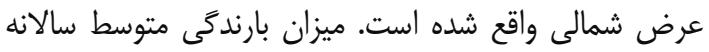

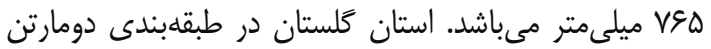

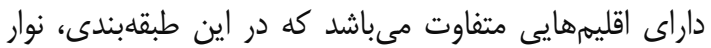

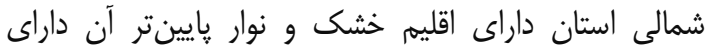

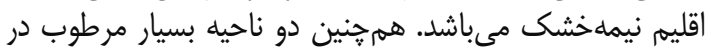

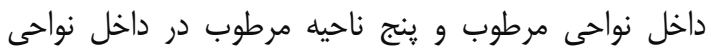

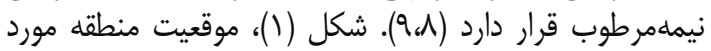

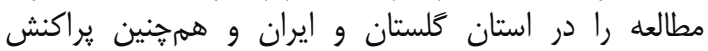

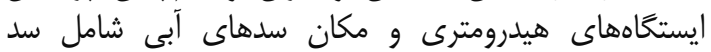

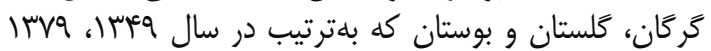

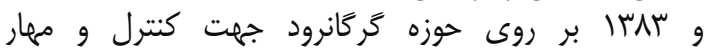
سيلابهاى مخرب احداث شدهاند، را در منطقه مورد مطالعه

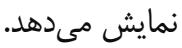

داراى اهميت ويزماى است (1). لذا هدف از يزوهش حاضر،

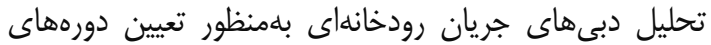

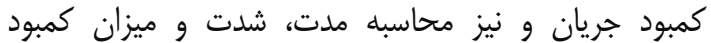

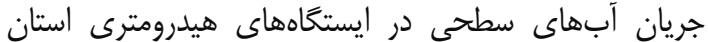

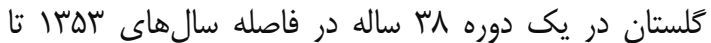

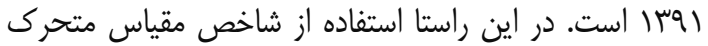

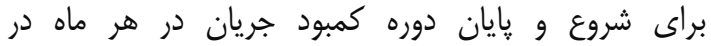

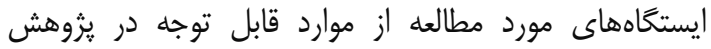

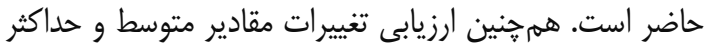

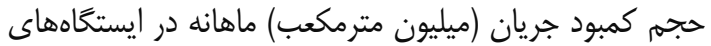
مورد مطالعه از اهداف يزوهش حيل حاضر است.

\section{مواد و روشها - مونها} موقعيت منطقه مورد مطالعه در يثروهش حاضر، حوزه آبخيز كَركانرود در استان كَلستان

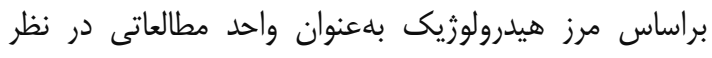

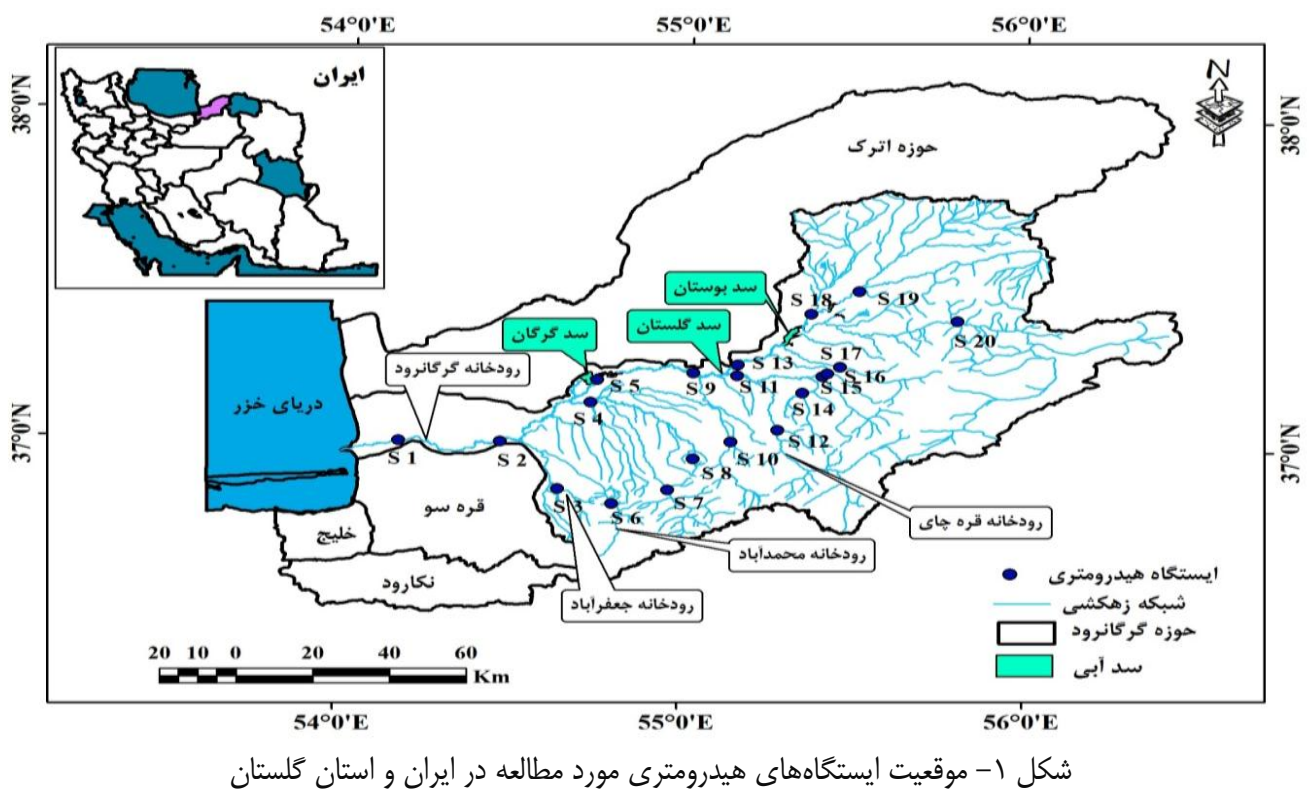

Figure 1. Location of the study area and river gauge stations in Iran and Golestan Province

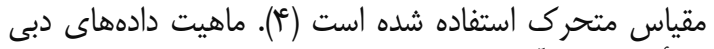

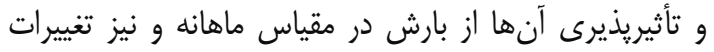

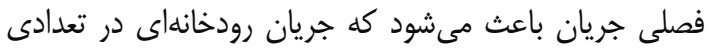

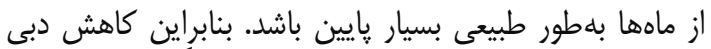

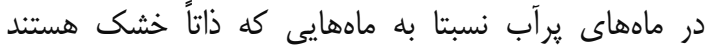

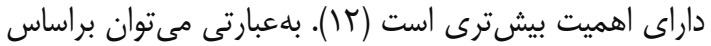

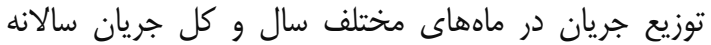

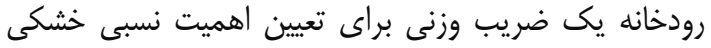

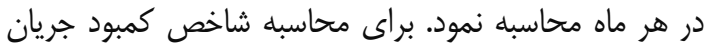
و با استفاده از دادههاى دبى ماهانه، از رابطه (1) استفاده شده

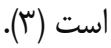

در يزوهش حاضر ابتدا آمار دبى ماهانه • ب ايستخاه

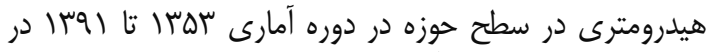

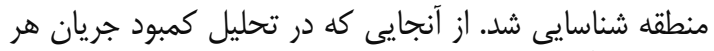
جه دوره آمارى ايستخاهها بيشتر باشد دائ دقت نتايج دقيقتر

\section{روش تحقيق}

در تحليل دورههاى كمآبى جريان رودخانهاى روشهاى دائي

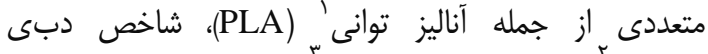

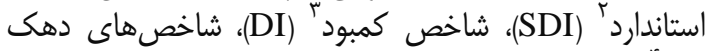

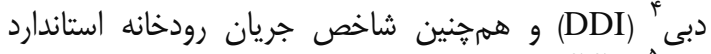

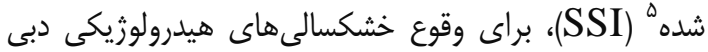

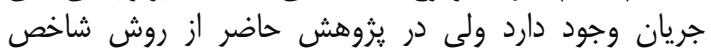


مىباشد. رابطه ارايه شده براى تعيين شروع خشكى در ماه ماه

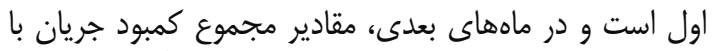

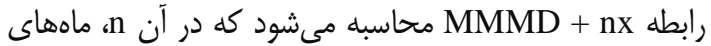

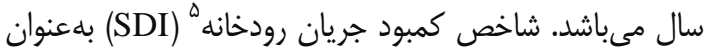

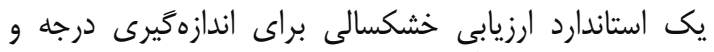

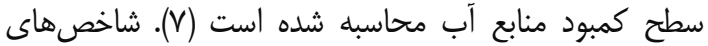

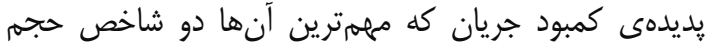

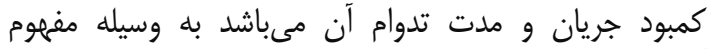

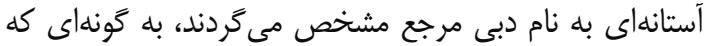

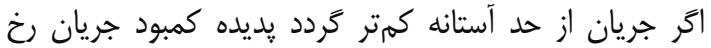

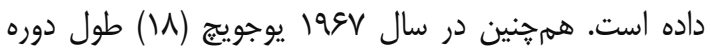

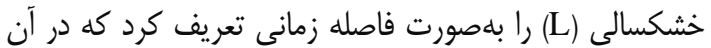

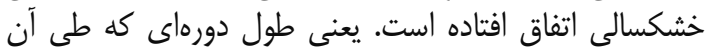

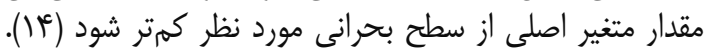

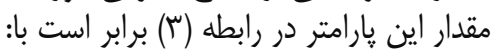

$\mathrm{L}=\mathrm{D}_{\mathrm{e}}-\mathrm{D}_{\mathrm{s}}$

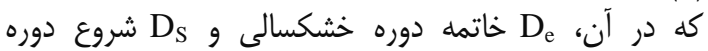

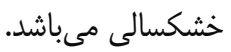

\section{نتايج و بحث}

همانطور كه در يروهش حاضر ذكر كرديد برديد، تغييرات

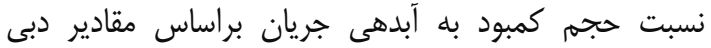

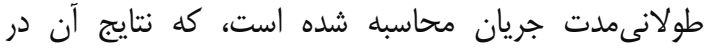
مقياس ماهانه در شكل (T) ارايه شده است.
$\mathrm{W}(\mathrm{t})=0.1\left(1+\frac{M(t)}{\frac{1}{12} \times M A D_{d i s}}\right)$

كه در آن، M(t) ميانگين دبى هر ماه، MAD

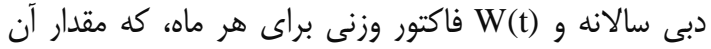

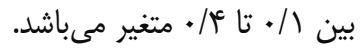

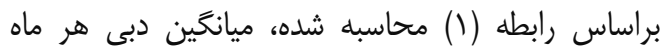

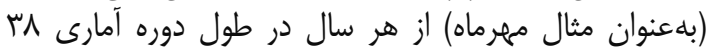

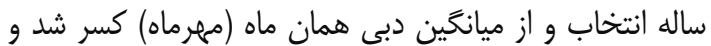

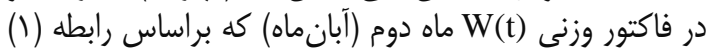

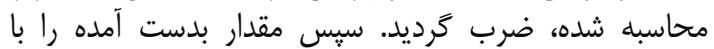

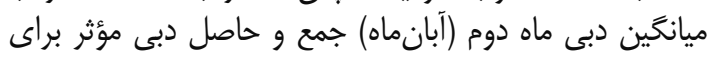

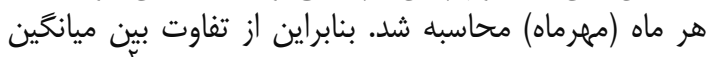

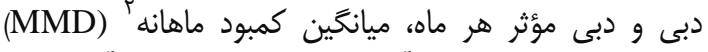

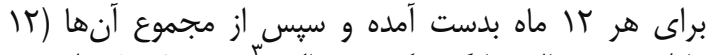
ماه) در هر سال ميانكين كمبود سالانه (MAD

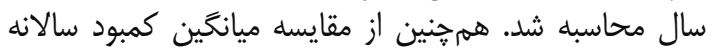

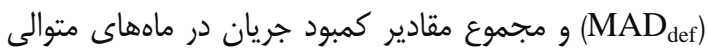

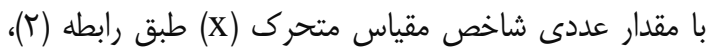

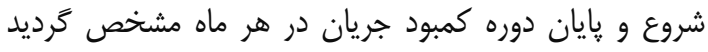
$\mathrm{X}=\frac{M A D_{d e f}-M M M D}{11}$

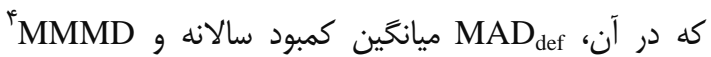
ماكزيمه ميانكين دبى ماهانه در هر سال و X مقياس متحرك

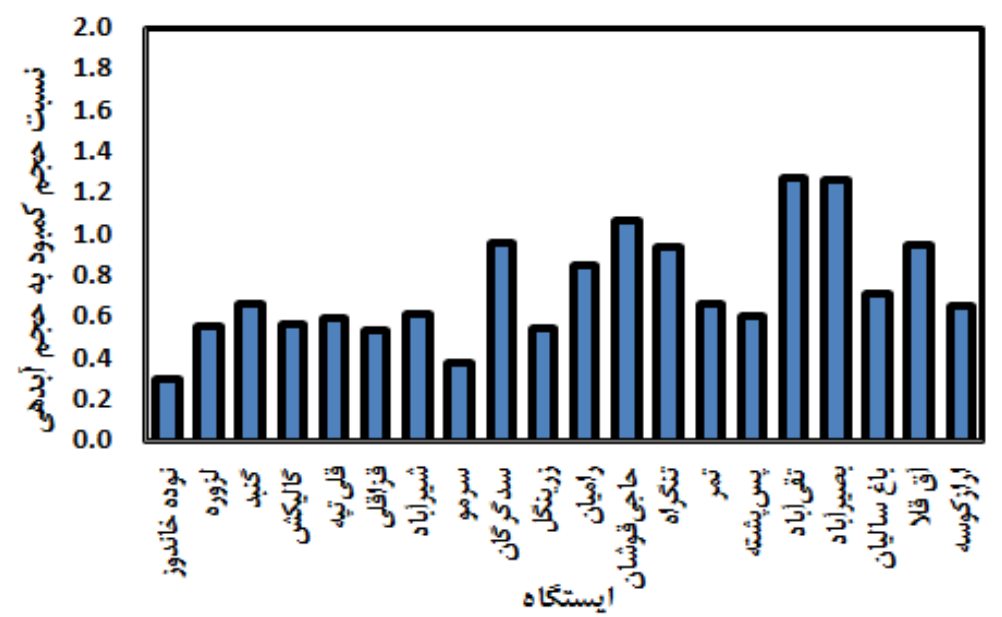

شكل r- مقادير نسبت حجم كمبود به حجم آبدهى در ايستخاههاى هيدرومترى حوزه آبخيز كر كانرود

Figure 2. The amount of flow deficit volume to discharge ration in hydrometric stations of Gorganroud Basin

ايستخاهها رخ داده است. در حالى كه در ايستخاههاى نوده

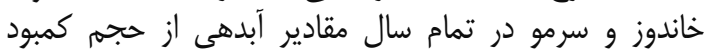

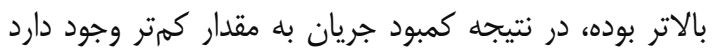

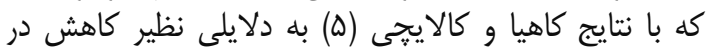

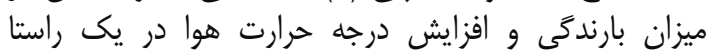

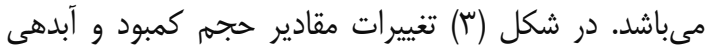

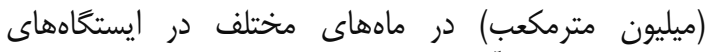
هيدرومترى حوزه آبخيز كَر كانرود ارايه شده است.

1- Mean Annual Discharge (MADdis)

3- Mean Annual Deficit (MADdef)

5- Streamflow Deficit Index (SDI)
براساس نتايج نسبت حجم كمبود جريان به مقادير آبدهى

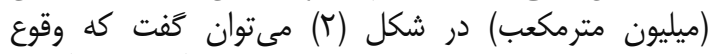

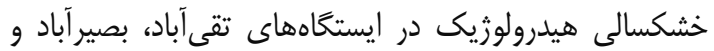

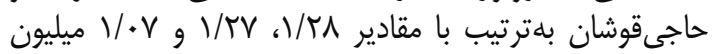

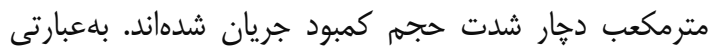

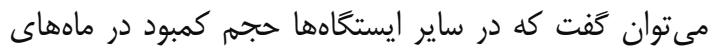

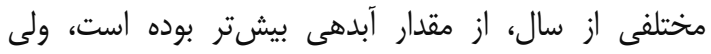
بيشترين مقدار تغييرات در ايستخاههاى مذكور نسبت به ساير آنس

2- Mean Monthly Deficit (MMD)

4- Maximum Mean Monthly Discharge (MMMD) 

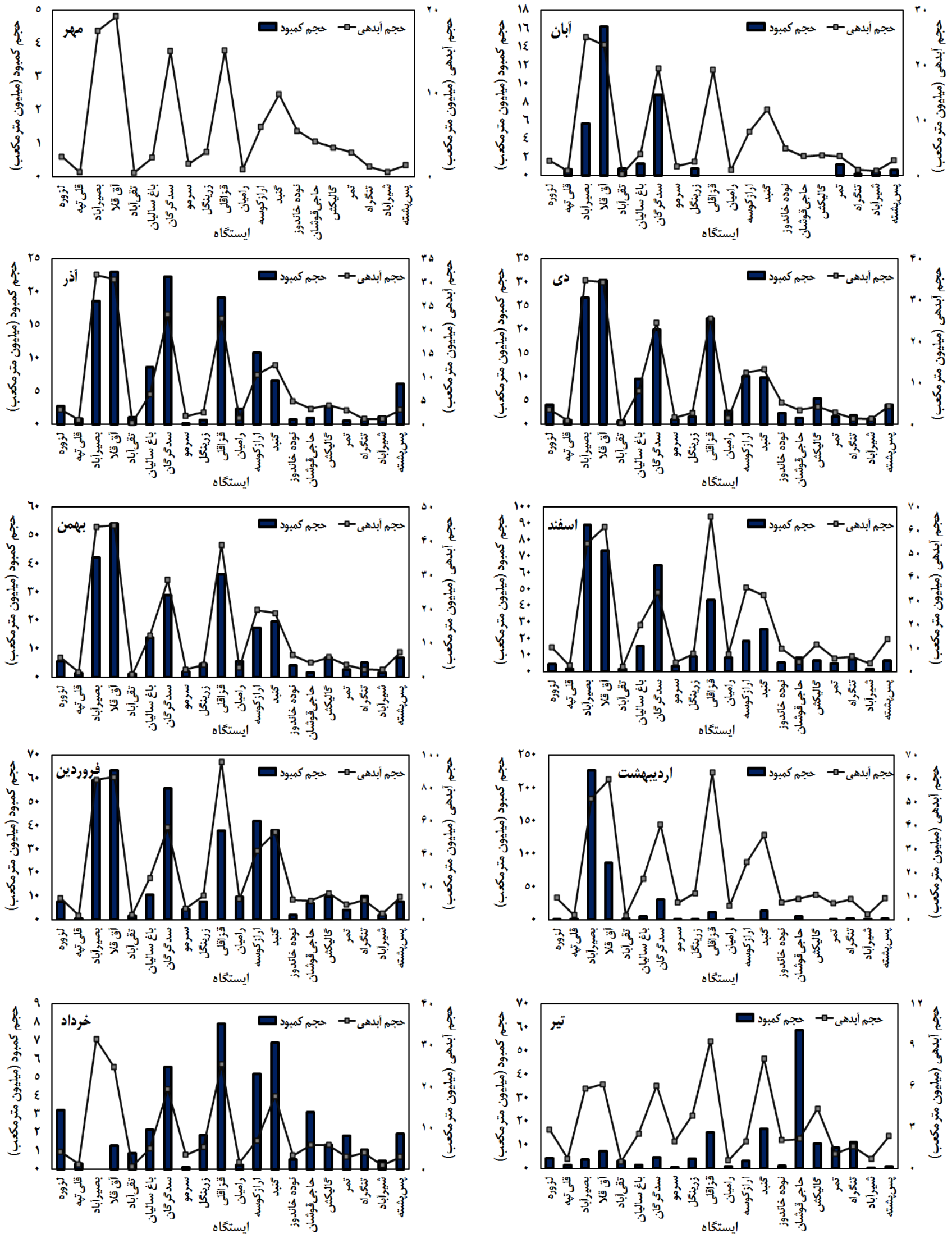

شكل س- تغييرات مقادير حجم كمبود و آبدهى (ميليون مترمكعب) در ماههاى مختلف در ايستخاههاى هيدرومترى حوزه آبخيز گر گَانرود

Figure 3. Variations of monthly flow deficit volume and discharge (million cubic meters) in hydrometric stations of Gorganroud Basin 

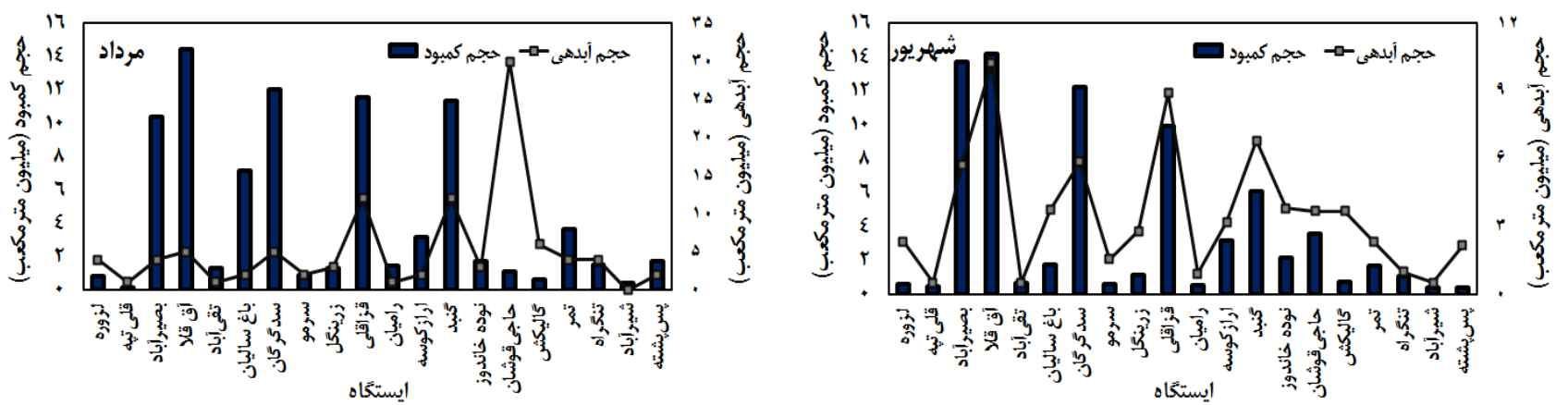

ادامه شكل ب- تغييرات مقادير حجم كمبود و آبدهى (ميليون مترمكع) در ماههاى مختلف در ايستكاههاى هيدرومترى حوزه آبخيز كَ كانرود Contued Figure 3. Variations of monthly flow deficit volume and discharge (million cubic meters) in hydrometric stations of Gorganroud Basin

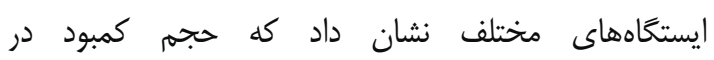

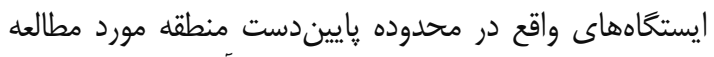

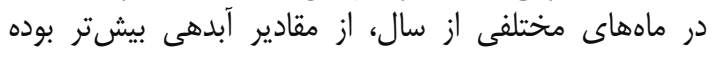

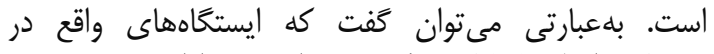

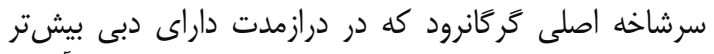

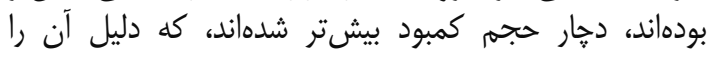

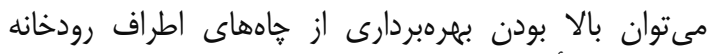

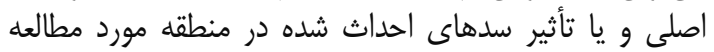

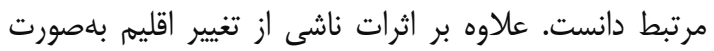

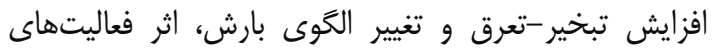

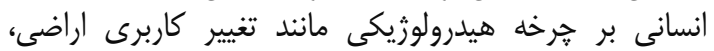

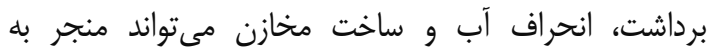

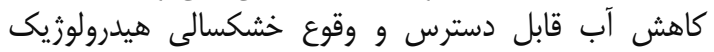

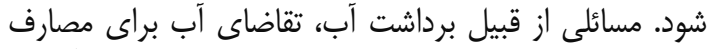

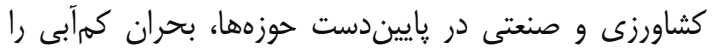

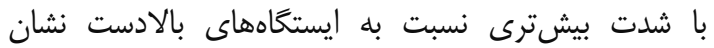

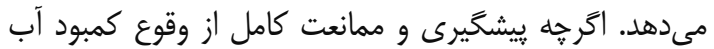

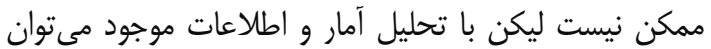

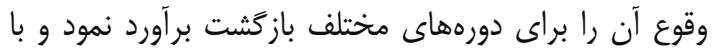

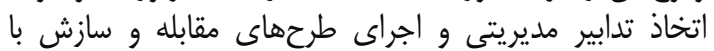
خشكسالى تأثيرات و ييامدهاى ناشى از آن را كاهش دان داد.

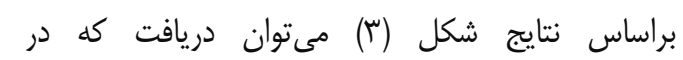

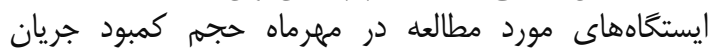

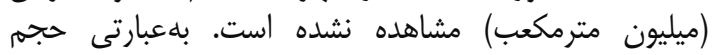

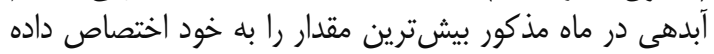

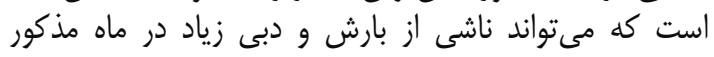

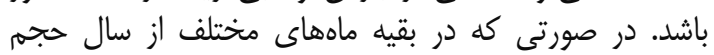

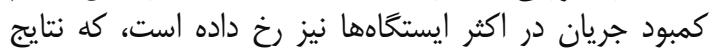

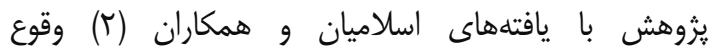

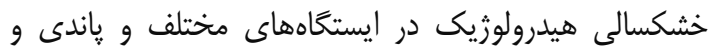

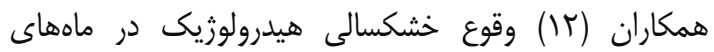

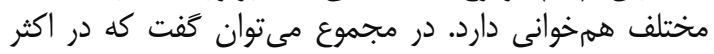

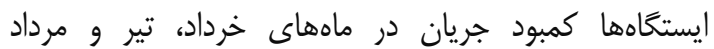

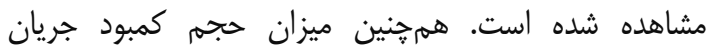

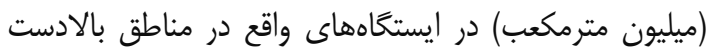

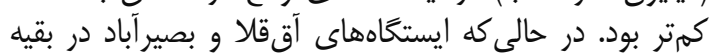
ماههاى سال داراى بيشترين مقدار حجم كمبود جريان

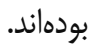

در اين يزوهش با استفاده از دادهاي دبى داريى ماهانه،

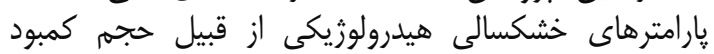

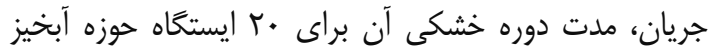

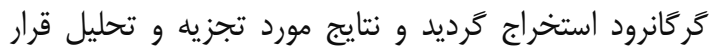
كرفت. تحليل ارتباط بين مقادير حجم كمبرد مورد تجرية وريان آب در 

flow deficit intensity in Gorganroud Watershed, Iran. Ecopersia, 4(1): 1313-1330 (In Persian).

2. Eslamian, S.S., M. Ghasem and S. Soltani-Gerdefaramarzi. 2012. Computation and regionalization of low flow indices and determination of hydrological drought durations in Karkhe Watershed, Journal of Science and Technology of Agriculture and Natural Resources, Water and Soil Science, 16(59): 114 (In Persian).

3. Herbst, P.H., D.B. Bredenkamp and H.M.G. Barker. 1966. A technique for the evaluation of drought from rainfall data. Journal of Hydrology, 4: 264-272.

4. Hisdal, H., L.M. Tallaksen, B. Clausen, E. Peters and A. Gustard. 2004. Hydrological drought characteristics in developments in water science. Amsterdam, the Netherlands: Elsevier Science, 48: 139-198.

5. Kahya, E. and S. Kalayci. 2004. Trend analysis of streamflow in Turkey. Journal of Hydrology, 289(1-4): 128-144.

6. Karimi, M., K. Shahedi and M. Byzedi, 2015. Analysis of hydrological drought using constant threshold level method (Case Study: Karkheh River Basin, Iran). Journal of Watershed Management Research, 6(11): 59-72 (In Persian).

7. Li, R., L. Cheng, Y. Ding, K. Khorasani, Y. Chen and W. Wang. 2013. An operational drought risk management framework based on stream-flow intelligent internet control. Journal of Risk Analysis and Crisis Response, 3(1): 34-43.

8. Mosaedi, A., M. Khalili Zade and A. Mohammadi. 2008. Drought monitoring in Golestan Province, Journal of Agricultural Sciences and Natural Resources, 15(2): 176-183 (In Persian).

9. Mostafazadeh, R. and V.B. Sheikh. 2010. Rain-gauge density assessment in Golestan province using spatial correlation technique, Watershed Management Research (Pajouhesh and Sazandegi, 93: 79-87 (In Persian).

10. Mostafazadeh, R., M. Vafakhah and M. Zabihi. 2016. Analysis of monthly wet and dry spell occurrence by using power laws in Golestan Province, Iran. Iranian Journal of Ecohydrology, 3(1): 112 (In Persian).

11. Ochoa-Rivera, J., J. Andreu and R. García-Bartual. 2007. Influence of inflows modeling on management simulation of water resources system. Journal of Water Resources Planning and Management, 133: 106-116.

12. Pandey, R.P., S.K. Mishra, R. Singh and K.S. Ramasastri. 2008. Streamflow drought severity analysis of Betwa River System (India). Water Resources Management, 22: 1127-1141.

13. Shafiei, M. and M. Raeini-Sarjaz. 2015. Assessment of the impact of meteorological drought and wetness trends on the Parishan Lake water level decline. Journal of Watershed Management Research, 6(12): 118-126 (In Persian).

14. Shahrokh, V. andi S.M.M. Lashanizand and M. Khakpour. 2009. A survey of hydrological droughts and its relationship with precipitation in the basins of Khorramabad Rivers, Quarterly Environmental Based Territorial Planning (Amayesh), 2(6): 140-155 (In Persian).

15. Smakhtin, V.U. 2001. Low flow hydrology: a review". Journal of Hydrology, 240: 147-186.

16. Van Huijgevoort, M.H.J., H.A.J. Van Lanen, A.J. Teuling and R. Uijlenhoet. 2014. Identification of changes in hydrological drought characteristics from a multi-GCM driven ensemble constrained by observed discharge. Journal of Hydrology, 512: 421-434.

17. Van Loon, A.F. and G. Laaha. 2015. Hydrological drought severity explained by climate and catchment characteristics. Journal of Hydrology, 526: 3-14.

18. Yevjevich, V. 1967. An objective approach to definition and investigations of continental hydrologic droughts. Hydrology papers, Colorado State University, Fort Collins, USA, 23 pp.

19. Zaidman, M., H. Rees and A. Young. 2002. Spatio-temporal development of streamflow droughts in North-West Europe. Hydrology and Earth System Sciences Discussions, 6(4): 733-751. 


\title{
Estimating the Monthly Flow Deficit during Hydrological Drought Periods in Gorganroud River Basin
}

\author{
Raoof Mostafazadeh $^{1}$, Khadijeh Haji ${ }^{2}$, Abazar Esmali-Ouri ${ }^{3}$ and Shahnaz Mirzaei ${ }^{4}$ \\ 1- Assistant Professor, Faculty of Agriculture and Natural Resources, University of Mohaghegh Ardabili, \\ (Corresponding author: raoofmostafazadeh@uma.ac.ir) \\ 2, 3 and 4- M.Sc. Student, Associate Professor and Graduated M.Sc. Student, Faculty of Agriculture and Natural \\ Resources, University of Mohaghegh Ardabili \\ Received: June 3, $2016 \quad$ Accepted: June 12, 2017
}

\begin{abstract}
Hydrological drought usually have a considerable impact on the quantity and quality of water resources, causing water shortages in consumption sector and its study is important in terms of intensity, frequency and spatial extent. The aim of this study is to determine the periods of hydrological droughts, drought characteristics and amount of flow deficit in a 38-year recorded data over hydrometric stations of the Golestan Province. The weighting factor of drought importance for each month was calculated based on the flow distribution in different months. The subtracted mean discharge of particular month from the long-term average was multiplied by the weighting factor to determine the effective discharge. The difference of mean monthly discharge and effective discharge considered as monthly flow deficit. The onset and end of hydrological drought periods were defined and the cumulated flow deficits were calculated. The results showed that the highest flow deficit amounts were recognized for in Taghiabad, Basirabad, and Hajighoshan stations with $1.28,1.27$, and 1.07 respectively. In general, the flow deficit were observed in June, July and August in almost all river gauge stations of the study area. Moreover, the deficit volume was lower at stations located in upland areas.
\end{abstract}

Keywords: Flow variation, Deficit volume, Threshold level, Hydrological drought, Flow deficit 